\title{
开花后水分调控对两个筋型冬小麦 品种品质与产量的影响
}

\author{
彭 羽 $1^{12}$ 郭天财 ${ }^{1}$ 蒋高明 $2^{*} \quad$ 王晨阳 $^{1} \quad$ 李永庚 $^{2} \quad$ 张学林 $^{12}$ \\ (1 国家小麦工程技术研究中心, 郑州 450002) \\ (2 中国科学院植物研究所植被数量生态学重点实验室, 北京 100093)
}

\begin{abstract}
摘 要 通过开花后不同水分处理研究了两个不同筋型冬小麦品种“( 豫麦 34’ 和 洛阳 8716’) ( Triticum aestivum cv. “Yumai 34' and Luoyang 8716’) 的品质及产量变化。结果表明: 随着灌水时间推迟, 湿面筋含量、沉降值、面团形成 时间、稳定时间、评价值和拉伸面积有提高的趋势, 但是千粒重和产量下降, 随着开花后灌水量的增加，上述品质数 值又有减少, 产量及千粒重增加; 多次灌水处理与开花后灌 1 次水处理、开花后不灌水处理之间差异显著, 开花后 $21 \mathrm{~d}$ 和 $28 \mathrm{~d}$ 灌水处理的多项品质指标都大于不灌水处理。两品种面团稳定时间 (45\%和 $15 \%$ )、沉降值 (20\%和 $12 \%)$ 在不同水分处理下变异系数较大 吸水率、湿面筋、蛋白质含量变异系数 $(<10 \%$ 和 $<5 \%$ ) 较小。

关键词 灌浆期 水分 品质 冬小麦
\end{abstract}

\section{EFFECTS OF DIFFERENT WATER IRRIGATION SCHEMES AFTER ANTHESIS ON QUALITY OF TWO GLUTEN WINTER WHEAT VARIETIES}

\author{
PENG $\mathrm{Yu}^{12}$ GUO Tian-Cai ${ }^{1} \quad$ JIANG Gao-Ming ${ }^{2}$ \\ WANG Chen-Yang ${ }^{1} \quad$ LI Yong-Geng ${ }^{2}$ and ZHANG Xue-Lin ${ }^{1}{ }^{2}$ \\ (1 National Engineering Research Center for Wheat, Zhengzhou 450002, China) \\ (2 Laboratory of Vegetation Quantitative Ecology , Institute of Botany , Chinese Academy of Sciences , Beijing 100093 , China)
}

\begin{abstract}
The effects of different irrigation schemes in both the amount of water applied ( $45 \mathrm{~mm}$ water every time with maximum total $45-315 \mathrm{~mm}$ water) and the timing of water applications ( $7-28$ days) after anthesis on the quality characteristics of the strong gluten wheat (Triticum aestivum) ${ }^{6}$ Yumai $34^{\prime}$ and the soft gluten wheat Luoyang 8716' were studied in Zhengzhou and Luoyang experimental sites in Henan Province during the $1999-2001$ growing seasons. All natural precipitation was excluded from the controlled experiment. The experiment included eight irrigation treatments : irrigating on the 7th day , the 14th day , the 21st day , the 28th day , the 7 th day plus the 14 th day , the 7 th day plus the 21 st day after anthesis and a treatment of irrigating on the 7th, 14 th, 21 th and 28th days after anthesis and one treatment with no irrigation after anthesis. We summarize the main results below. 1) The content of wet gluten and sed.value increased by $12 \%-17 \%$ under the treatment of no irrigation and $21 \%-35 \%$ under a single, late water application following anthesis. In irrigation treatments that consisted of two or more applications after anthesis, increases were very small. The general tendency was that the greater the amount of water applied, the smaller the value of wet gluten and sed. value. 2) In irrigation treatments that consisted of only one application following anthesis, quality indicators such as dough development time, stability time, and valorimeter value, all increased (the increase ranged from $12 \%-76 \%$ in different cultivars and treatments) when irrigation was late ( $21-28$ days after anthesis $)$. These quality indicators all decreased when there was too much irrigation water ( $>90 \mathrm{~mm}$ ) or when applied more than one time. Soften degree became large when irrigation was high ( $>90 \mathrm{~mm}$ ). 3) Comparing values between the two cultivars, those of Yumai 34' were larger than those of Luoyang 8716' , including quality and yield. The variation coefficients of the strong gluten wheat' Yumai 34' were larger than those of weak gluten wheat Luoyang 8716' which showed that traits of Yumai 34' changed easily under changing environmental conditions. Changes in the coefficients of water absorption and wet gluten were very small and appeared to be affected mainly by genetics with little environmental effect. The correlated coefficients among sed.value , development time, stability time, and valorimeter value were positive and significant, but correlations between soften degree and other quality items were negative but not significant. 4) Irrigation treatments that consisted of one application only after anthesis tended to produce lower yields, and the later the irrigation time, the lower
\end{abstract}


the yields. In contrast, when the wheat was irrigated more than once, yields tended to increase and, in general , the more water applied, the greater the yields. Generally, under irrigation levels of $180-315 \mathrm{~mm}$ without natural precipitation, moderate increases in yield $\left(5792-8161 \mathrm{~kg} \mathrm{hm}^{-2}\right.$ ) were gained. Cultivar Yumai 34 ' has a greater yield potential under water conservation strategies whereas' Luoyang 8716' could realize higher yields under sufficient water supply. Considering the quality, yields and the water use efficiency, irrigating on 7th day or 14th day after anthesis was suitable for strong gluten wheat cultivars like Yuami34 to get high yield and quality. For weak gluten wheat cultivars , such as Luoyang 8716' , the best irrigation strategy was at least 2 application times after anthesis to improve yields and quality.

Key words Winter wheat , Grain filling stage , Irrigation , Quality

小麦 ( Triticum aestivum) 的面粉品质,包括营养 品质、加工品质以及面团流变学特性 (卢良恕, 1993 ) ,受品种本身遗传特性(Tohansson et al . ,2001) 和外界生态因素共同作用的影响 (金善宝, 1996; 郭 天财等 ,1988)。温度 (Rharrabti et al .,2003)、光照 (Mikhaylenko et al. 2000)、水分 (Nagarajan , 1999)、 土壤 (毛凤梧等,2001)、肥料 (López-Bellido et al. , 2001)、轮作 ( Panozzo \& Eagles, 2000)、病虫害 (王鸿 等 2000; Mekendry et al. , 1995)、播期播量 ( Singh , 2000 ) 等环境条件都影响小麦面粉的品质, 最终食用 品质好坏还取决于加工工艺水平 (张宝军等,1995; Anjunm \& Drake 2000)。研究表明，小麦生育期间在 外界环境因素中, 以氮肥和水分对品质影响最大, 其 次是气候和土壤条件 (Rharrabti et al , , 2003 汪永钦 等,1990 刘尊英等,1999)。外界因素对小麦品质的 影响，主要是在冬小麦品质形成的关键时期(抽穗期 ～成熟期)内, 其中, 尤以温度和水分的影响作用最 大(陈如梅等, 1992; 李永庚等, 2003; Tribioi et al. , 2000) 沉降值受干旱的影响比受温度的影响要大 (Corbellini et al. 1997)。后期水分对蛋白质含量影 响的研究较多。研究(章练红等, 1984; 曹广才等, 1994 ; 梁银丽等 2000)表明，小麦生育期间降水量与 小麦蛋白质含量呈负相关，多雨年份小麦籽粒蛋白 质含量降低，干旱年份容易形成高蛋白籽粒，但是降 低产量。如加拿大 Auan 等利用 14 年的数据研究了 加拿大干旱带 7 个点 4 月 1 日至 8 月 3 日降雨量及 其分布对小麦蛋白质的影响, 发现蛋白质含量剩余 变异的 34\%可归因于降雨的变化(曹广才等, 1994)。 国外研究多采用水分胁迫处理造成干旱环境。加拿 大 Sosulsk 的试验表明 增加水分胁迫程度提高蛋白 质含量 25\%(曹广才等,1994)。王绍中等人关于 60 个试点、3个品种的研究说明, 随冬前 9、10 月降雨 量增加 (超过 $100 \mathrm{~mm}$ ) , 小麦蛋白质含量呈明显下降 趋势(靳华芬,1992)。干旱条件下, 灌水对小麦品质 有不同影响，欠水年可提高籽粒产量、蛋白质含量和 赖氨酸含量; 丰水年灌水过多会降低蛋白质含量。
适宜的灌溉管理, 特别是花期以后的水分条件显著 影响小麦的食用品质(赵乃新等,1998)。后期降雨 过多易冲掉根部硝酸盐, 使氮供应不足, 营养物质运 转的时间拖长, 降雨使淀粉产量增加, 导致籽粒蛋白 质含量降低(章练红等,1993)。大量生态试验(曹广 才等, 1994) 认为, 在天然降雨对籽粒蛋白质的积累 不占主导地位的地区和试点，其作用不明显，但在天 然降水成为限制因子的地区, 降水量多可能导致籽 粒蛋白质的低含量, 长江中下游地区就属于此种情 况。

若把灌溉与增施氮肥相结合, 则籽粒产量和蛋 白质含量同时增长, 或至少蛋白质含量不下降。澳 大利亚的 Dala 等研究表明(荆奇等,1999) ,灌溉条 件下施氮可提高蛋白质含量, 在施氮 $50 \mathrm{~kg} \mathrm{~m}^{-2}$ 水平 下, 籽粒蛋白质含量为 $10 \%$ ，当施氮量提高到 $200 \mathrm{~kg}$ $\mathrm{m}^{-2}$ 时，籽粒蛋白质含量递增到 $14.4 \%$ 。另据土耳 其的施氮施磷和灌溉的复裂区试验结果, 在适氮条 件下灌水增产效果显著, 对籽粒蛋白质的含量影响 不显著。同时,许多研究 (Mikhaylenko et al.,2000; Anjunm \& Drake 2000 ; Irani , 1998 ; 章练红 ,1988)认 为，一般情况下，灌水增加籽粒产量和蛋白质产量， 但是由于增加了籽粒产量对蛋白质的稀释作用, 而 使蛋白质含量有所下降。千旱在多数情况下会使蛋 白质含量有所提高, 却使籽粒产量和蛋白质产量降 低。在较干旱时, 肥料充足可使蛋白质含量提高, 肥 料不足时干旱或湿润都可以使蛋白质含量降低。关 于后期水分对其它品质的影响, Rharrabti 等 (2003) 根据 10 个品种在西班牙南北 10 个不同干湿地块的 试验, 发现灌浆期灌水对品质有负效应, 灌水处理的 沉降值、蛋白质含量有不同程度的降低, 灰分含量则 提高。Mikhaylenko 等 (2000) 研究表明, 半干旱地区 小麦蛋白质含量、沉降值、面包体积大于多降水区。 Fullington 等(1987) 认为, 在灌浆末期灌水, 沉降值、 籽粒蛋白质含量均有不同程度的降低, 郜俊红等 (2003) 用强筋小麦 豫麦 34', 每次灌水 $60 \mathrm{~mm}$, 分别 在越冬、返青、拔节、灌浆期处理 结果发现在灌足底 
墒水条件下，不灌越冬水、返青水、拔节水，控制灌浆 水, 蛋白质含量、湿面筋、沉降值、面团稳定时间等品 质数值均有一定程度的提高, 产量小幅度下降。但 是也有不同试验结果, 毛凤梧等 (2001) 用灌浆期灌 水结合施用氮素处理, 发现灌浆期浇水, 可使籽粒的 容重、粗蛋白、赖氨酸、出粉率提高, 面粉的沉降值、 湿面筋、干面筋、形成时间、稳定时间增加 弱化度有 一定程度的下降。并指出灌浆期灌水可以提高叶绿 素含量和硝酸还原酶活性，从而促进籽粒内氮素的 代谢、转化和积累, 进而影响籽粒面团流变学特性。 Mann 等(2001) 试验表明灌浆末期干旱导致面团形 成时间降低, 面筋弹性降低, Gooding 等 (2003) 试验 表明灌浆末期干旱降低 SDS-沉降值。

由此可以看出, 后期水分对品质影响已经有很 多研究, 但是研究多集中在大田试验, 完全控制降水 试验较少, 而且后期具体灌水量、灌水时间尚不统 一, 对蛋白质含量研究较多而对其它品质研究较少, 且研究结论也有不一致的地方。本试验在前人研究 的基础上，在完全控制天然降水的条件下，通过人工 控制灌水量和灌水时期, 对后期水分变化影响小麦 的面团流变学特性方面作一下探讨, 以期为小麦品 质生态研究提供参考。

\section{1 材料和方法}

\section{1 实验设计}

试验于 $2000 ２ 001$ 年度在中国农业科学院洛 阳旱农试验基地进行, 试验土质为壤土, 有机质含量 为 $1.418 \%$, 全氮含量为 $0.0898 \%$, 全磷含量为 $0.0827 \%$ 。试验各小区间用四层防侧渗塑料隔至 $200 \mathrm{~cm}$ 深, 下不封底, 小区面积为 $2 \mathrm{~m}^{2}$, 该区地下水 位为 $4 \sim 5 \mathrm{~m}$ 。

供试品种为强筋型优质小麦 豫麦 34' 和弱筋 型小麦 洛阳 $8716^{\prime}$ ，试验共设 8 个水分处理 播种前 浇灌底墒水、越冬期浇灌冬水、孕穗期浇灌孕穗水。 每个处理灌水情况见表 1 , 以开花后不灌水为对照 处理 $(\mathrm{CK})$ 。试验地播前基肥施鸡粪为 $1.875 \mathrm{~g}$ $\mathrm{m}^{-2}, \mathrm{~K}_{2} \mathrm{O}$ 为 $0.165 \mathrm{~g} \mathrm{~m}^{-2}, \mathrm{P}_{2} \mathrm{O}_{5}$ 为 $0.138 \mathrm{~g} \mathrm{~m}^{-2}$, 氮 肥为 $0.27 \mathrm{~g} \mathrm{~m}^{-2}$ 。孕穗期追肥, 基肥与追肥之比为 $1: 1$ 。试验裂区设计, 分不同灌水时间和不同灌水次 数处理, 随机排列, 重复 3 次。每小区播种 5 行, 播 种密度按每行 90 个基本苗。全生育期防止天然降 水, 遇雨雪即推上防雨棚。

\section{2 采样与分析}

按照各个小区收获脱粒, 籽粒放置 1 个月后按
照各个处理小区混合，按照四分法取样, 测定各品质 指标, 用 Brabender senior 实验磨制粉。籽粒蛋白质 含量的测定, 高速粉碎机粉样后, 用日本 VS-KT-P 型 全自动定氮仪测定全氮含量 然后乘以系数 5.83 换 算成粗蛋白含量。湿面筋测定, 用瑞典 Falling Number 公司 2100 型面筋仪, 方法参照 AA-CC 标准 NO. 38-32 ZZeleny 沉降值测定采用 $3.2 \mathrm{~g}$ 面粉按照 AA-CC 标准 56-61A 机械震荡法 ;面团粉质参数用 Brabender 公司粉质仪和拉伸仪测定，见 GB/T14614-93 方法; 面团拉伸参数用 Brabender 公司拉伸仪测定，见 GB/ T14615-93 方法，收获后小区计产并进行室内考种， 分析产量及产量相关因素。土壤水分含量用土钻法 测量, 分别于播前一天、收获后一天测定 $0 \sim 150 \mathrm{~m}$ 土层每 $20 \mathrm{~cm}$ 土层水分含量, 耗水量按照农田水分 平衡方程式(兰林旺等, 1995)计算;水分利用效率按 照单位面积小区的经济产量与耗水量之比求得。

表 1 试验处理设计

Table 1 Experimental design

\begin{tabular}{|c|c|}
\hline $\begin{array}{l}\text { 处理名称 } \\
\text { Treatments }\end{array}$ & $\begin{array}{c}\text { 灌水时间与次数 } \\
\text { Irrigating time and times }\end{array}$ \\
\hline $7 \mathrm{~d}$ & 花后 $7 \mathrm{~d}$ The 7 th day after anthesis \\
\hline $14 \mathrm{~d}$ & 花后 $14 \mathrm{~d}$ The 14th day after anthesis \\
\hline $21 \mathrm{~d}$ & 花后 $21 \mathrm{~d}$ The 21th day after anthesis \\
\hline $28 d$ & 花后 $28 \mathrm{~d}$ The 28th day after anthesis \\
\hline$(7+14) d$ & $\begin{array}{l}\text { 花后 } 7.14 \mathrm{~d} \\
\text { The } 7 \text { and 14th day after anthesis }\end{array}$ \\
\hline$(7+21) d$ & $\begin{array}{l}\text { 花后 } 7.21 \mathrm{~d} \\
\text { The } 7 \text { and } 21 \text { th day after anthesis }\end{array}$ \\
\hline$(7+14+21+28) d$ & $\begin{array}{l}\text { 花后 } 7 、 14 、 21 、 28 \mathrm{~d} \\
\text { The } 7,14,21 \text { and } 28 \text { day after anthesis }\end{array}$ \\
\hline CK & 花后不灌水 No irrigating after anthesis \\
\hline
\end{tabular}

\section{2 实验结果}

\section{1 湿面筋含量}

图 1 表明，强筋小麦品种 豫麦 34'各处理的湿 面筋含量均显著的比弱筋小麦品种 洛阳 8716 ' 高。 湿面筋含量的差异“, 豫麦 34 ' 以处理 $21 \mathrm{~d}$ 和 CK 较 高，分别达 $41.0 \%$ 和 $40.7 \%$ ，以花后灌 4 水的处理 最低, 为 $36.2 \%$, 其余各处理间的湿面筋含量差异 不大 均在 38\% 左右。“洛阳 8716’ 表现趋势相同。

\section{2 沉降值}

与湿面筋一样 强筋型小麦品种 豫麦 34' 各处 理的沉降值均比弱筋型小麦品种 洛阳 8716' 高, 其 提高幅度为 $14.3 \sim 26.2 \mathrm{ml}$ 。两种筋型小麦品种花 后不同水分各处理中 均以 $\mathrm{CK}$ 和处理 $28 \mathrm{~d}$ 的沉降 值较高, 处理 $(7+14+21+28) \mathrm{d}$ 的沉降值最低, 其 

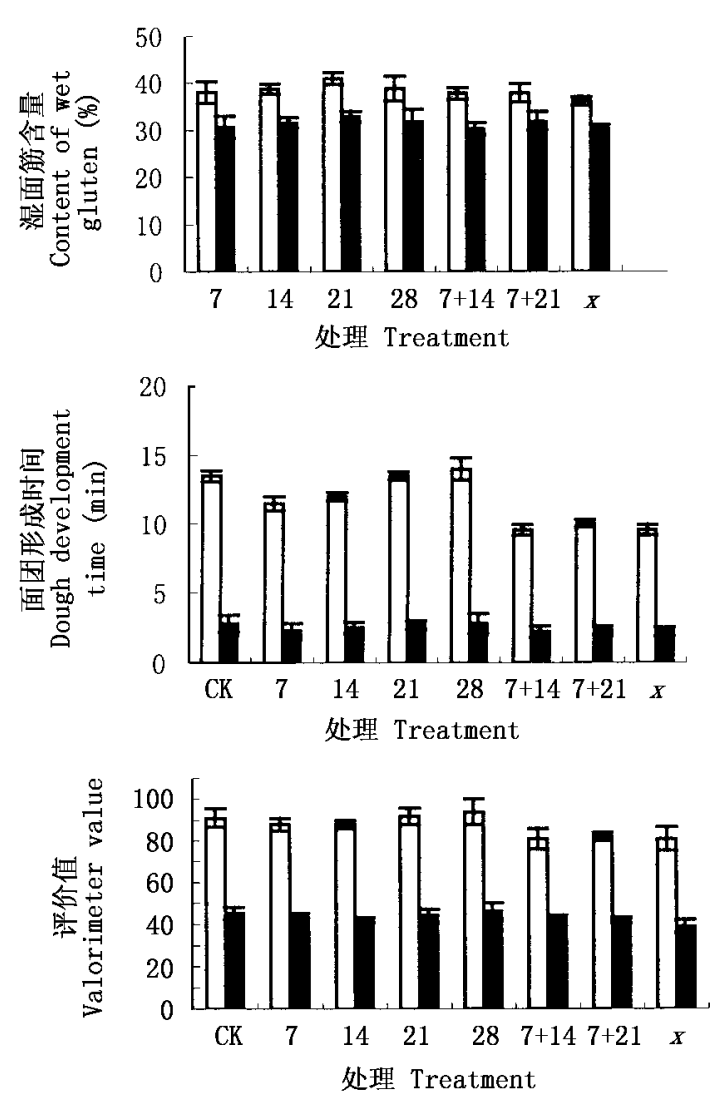
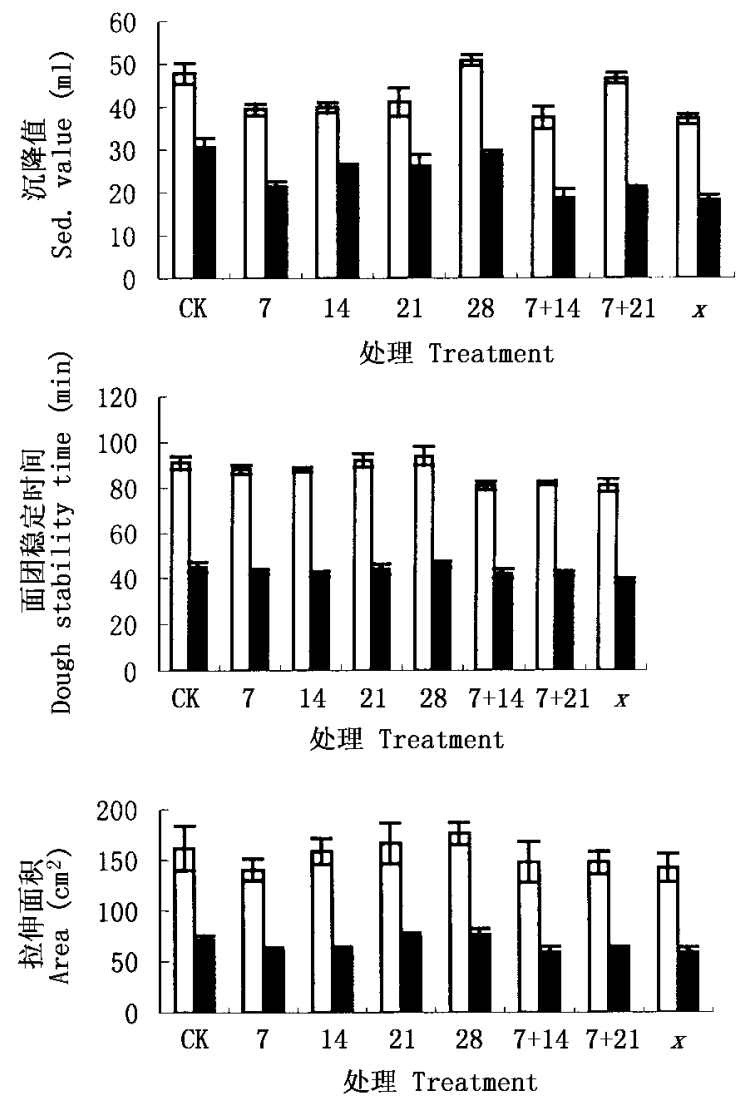

图 1 两小麦品种不同水分条件下的品质变化

Fig. 1 The changes of quality traits of two varieties under different water treatments

$\square$ 豫麦 34' ' Yumai 34'

洛阳 8716' ' Luoyang 8716”

$7: 7$ d $14: 14$ d $21: 21$ d $28: 28$ d $7+14:(7+14)$ d $7+21:(7+21)$ d $\quad x:(7+14+21+28)$ d

极差分别为 $13.6 \mathrm{ml}$ 和 $12.3 \mathrm{ml}$ 。在同一处理中, 两 品种沉降值相差最大的处理为 $(7+21) \mathrm{d}$, 差值达 $26.2 \mathrm{ml}$, 差异达到显著水平; 相差最小的处理为 14 $\mathrm{d}$, 差值为 $14.3 \mathrm{ml}$ 。

\section{3 面团形成时间}

面团形成时间是从加水开始直至达到峰值 (500 E.U.)的时间，反映面团弹性。图 1 表明，两种筋型 小麦品种表现趋势基本一致,花后灌 1 次水的 4 个 处理，面团形成时间均随灌水时间推迟而显著增加， 豫麦 34 ” 由 $11.5 \mathrm{~min}$ 增加到 $14 \mathrm{~min}$,增加了 2.5 $\min$; 洛阳 8716 由 $2.3 \mathrm{~min}$ 增加到 $2.8 \mathrm{~min}$ 增加了 0.5 min , 说明强筋型小麦 豫麦 34’ 对灌水时间反应 较大', 洛阳 8716'则相对较小 花后灌水 2 次以上的 3 个处理中, 两种筋型品种均以 $(7+21) \mathrm{d}$ 处理的面 团形成时间略长,,$(7+14) \mathrm{d}$ 和 $(7+14+21+28) \mathrm{d}$ 两处理表现一致。

\section{4 面团稳定时间}

面团稳定时间指粉质谱线首次达到 500 E. U. 和离开 $500 \mathrm{E} . \mathrm{U}$.之间的时差。在一定范围内, 稳定
时间越长，烘烤面包品质也越好(曹广才等, 1994)。 图 1 表明，对 豫麦 $34^{\prime}$ 的稳定时间影响较大，最低 处理与最高处理相差达 $24 \mathrm{~min}$ 。开花后灌 1 次水, 有随灌水时间推迟，稳定时间提高的趋势。花后灌 水 2 次以上的处理均比花后灌 1 次水和 CK 处理要 小但处理间差别不大。

“洛阳 8716'不同水分处理的极差为 $0.6 \mathrm{~min}$, 远 远小于 豫麦 34', 说明受水分影响较小。与 豫麦 34 ' 的变化趋势一样“, 洛阳 8716'花后灌 1 次水, 随灌水 时间推迟, 面团稳定时间略有延长; 花后灌 2 次水以 上 3 个处理的面团稳定时间均低, 且处理间无差异。

\section{5 评价值}

评价值是综合反映面粉特性的代表性数值, 是 许多国家对面粉分类的依据。两种筋型小麦品种开 花后不同灌水处理的评价值表现为相同趋势, 即开 花后只 1 次灌水, 灌水时间越迟则评价值越高“, 豫 麦 34’ 从 88 提高到 94“; 洛阳 8716’ 从 43 提高到 46 ; 开花后灌 2 水处理 $(7+14) d 、(7+21) d$ 评价值均比 花后灌 1 水各处理为低, 开花后灌水 4 次的处理 (7 
$+14+21+28) d$ 值最低, 两品种分别为 81 和 39 。

2.6 拉伸面积

拉伸面积，即拉伸曲线下所包围的面积，是反映 面团强度的重要指标。比较两种筋型小麦品种花后 不同水分处理的拉伸面积可以看出,两种筋型小麦 品种的拉伸面积均以开花后灌 4 次水的处理为最 小; 开花后只灌 1 次水, 则随灌水时间后移, 拉伸面 积逐渐增加, 且两品种的拉伸面积均以处理 28 为最 高。以上表明, 开花后灌水次数增多、灌水量增大使 拉伸面积减少。

\section{7 变异系数}

图 2 表明“, 豫麦 34’ 变异系数较大的有弱化度 (122.8\%)、面团稳定时间 (44.8\%)、面团形成时间 $(16.0 \%)$ 和沉降值 $(12.1 \%)$, 其余品质指标的变异 系数都低于 $8 \%$, 说明软化度、面团形成时间、稳定 时间受外界环境影响较大。“洛阳 8716 '各品质指 标的变异系数都低于 $20 \%$,其中，较大的有沉降值 (19.7\%)、面团稳定时间（14.6\%)、抗延伸性 $(11.3 \%)$ ，表明不同水分处理对 洛阳 8716' 品质性 状的影响不及 豫麦 34' 明显。需要指出的是, 两品 种在不同水分处理下的出粉率、吸水率、延伸性、湿 面筋、蛋白质、评价值的变异系数都很低, 说明两种 筋型小麦品种上述品质指标与遗传特性关系密切; 而其它品质指标的变异系数较大, 说明不同筋力品 种的品质指标受后期水分调控的影响较大, 通过栽 培措施调控有较大改良潜力。

\section{8 各品质之间的相关性}

分析两种筋型小麦品种品质指标相关性, 出粉 率、软化度与多数品质指标之间呈不显著或显著的 负相关;面团形成时间、稳定时间、评价值、抗延伸
性、最大抗延伸性和拉伸面积, 分别与多数品质指标 之间呈不显著或显著正相关;沉降值、延伸性、湿面 筋含量与多数品质指标间相关性不显著。

\section{9 千粒重与产量}

表 2 表明,两品种千粒重变化较大, 均以 $(7+$ 14) $\mathrm{d}$ 处理的千粒重为最高, 并表现为浇水次数多的 处理大于浇水次数少的处理。在开花后只浇 1 次水 的 4 个处理中，处理 $7 \mathrm{~d}$ 和 $14 \mathrm{~d}$ 的千粒重均高且差 异不大, 而开花后一直没浇水的 CK 处理“, 洛阳 $8716^{\prime}$ 的千粒重均大于开花后只浇 1 次水的各处理， 但比花后灌 2 次水以上各处理低。表明“, 洛阳 $8716^{\prime}$ 在灌足底墒水和保证生育前期水分供应的情 况下, 开花后不浇水仍能获得较高的粒重。分析两 品种开花后不同水分处理的小麦产量“, 豫麦 34' 以 处理 $(7+14) d$ 、洛阳 8716 ' 以处理 $14 \mathrm{~d}$ 的产量最 高, 两品种均以 CK 和处理 $28 \mathrm{~d}$ 的产量最低。

\subsection{0 水分利用效率}

从表 2 可以看出,两品种开花后不同处理的水 分利用效率有随灌水次数增加和灌水时期后移而降 低的趋势。比较各处理水分利用效率“, 豫麦 34’ 的 变化幅度为 $1.57 \sim 2.22 \mathrm{~g} \mathrm{~mm} \mathrm{~mm}^{-1} \mathrm{~m}^{-2}$, 而洛阳 $8716^{\prime}$ 的变化幅度为 $1.29 \sim 2.05 \mathrm{~g} \mathrm{~mm}^{-1} \mathrm{~m}^{-2}$ 。说 明 豫麦 34'比 洛阳 8716' 的水分利用效率高。”豫 麦 34' 水分利用效率由高到低的顺序依次为 $7>\mathrm{CK}$ $>7>14>28>21>7+21>7+14+21+28$, 其中 7 、 $14 、 21 、 28 、 7+14 、$ CK 6 个处理的水分利用效率均在 $2.1 \mathrm{~g} \mathrm{~mm}^{-1} \mathrm{~m}^{-2}$ 以上; 而洛阳 8716 为 $\mathrm{CK}>14>21$ $>7>28>7+14>7+21>7+14+21+28$, 且不同处 理间水分利用率相差较大。比较两品种水分利用率 可以看出 ', 豫麦 34 ’ 水分利用效率较高, 在栽培管

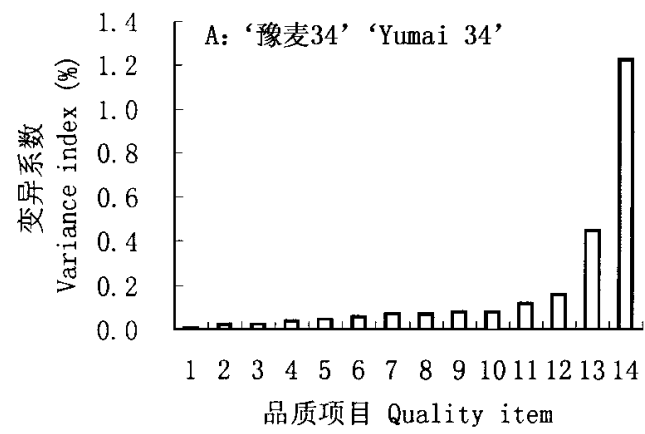

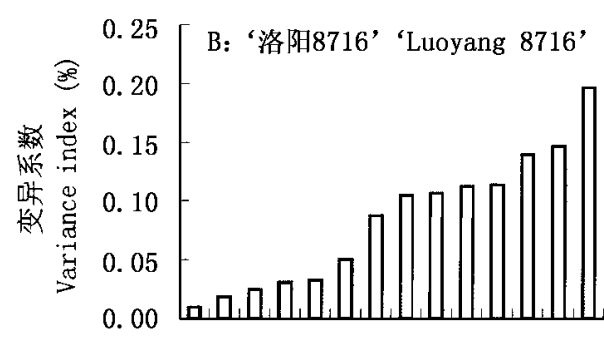

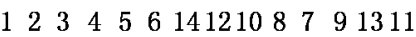
品质项目 Quality item

图 2 两品种品质在不同水分条件下的变异程度

Fig.2 The variance degree of quality in two varieties under different water conditions

1. 吸水率 Water absorption ratio 2 . 出粉率 Flour extraction ratio 3. 延伸性 Extensibility 4. 湿面筋 Wet gluten content 5. 蛋白质 Protein content 6. 评价值 Valorimeter value 7. 抗延伸性 Resistance 8. 最大抗延伸性 Maximum resistance 9. 比值 Ratio 10. 拉伸面积 Area 11. 沉降值 Sedimentation value 12. 形成时间 Development time 13. 稳定时间 Stability time 14. 弱化度 Soften degree 
表 2 开花后不同水分处理两品种小麦的千粒重与产量、水分利用效率

Table 21000 -grain weight, yield and water use efficiency of two varieties

\begin{tabular}{|c|c|c|c|c|c|c|}
\hline \multirow{2}{*}{$\begin{array}{c}\text { 处理 } \\
\text { Treatments }\end{array}$} & \multicolumn{2}{|c|}{$\begin{array}{c}\text { 千粒重 } \\
1000 \text {-grain weight }(\mathrm{g})\end{array}$} & \multicolumn{2}{|c|}{$\begin{array}{c}\text { 产量 } \\
\text { Yield }\left(\mathrm{g} \mathrm{m}^{-2}\right)\end{array}$} & \multicolumn{2}{|c|}{$\begin{array}{c}\text { 水分利用效率 } \\
W U E\left(\mathrm{~g} \mathrm{~mm}^{-1} \mathrm{~m}^{-2}\right)\end{array}$} \\
\hline & $\begin{array}{l}\text { ‘ 豫麦 34’ } \\
\text { ‘ Yumai 34' }\end{array}$ & $\begin{array}{c}\text { ‘ 洛阳 8716’ } \\
\text { ‘ Luoyang 8716’ }\end{array}$ & $\begin{array}{l}\text { ‘豫麦 34’ } \\
\text { ‘ Yumai 34’ }\end{array}$ & $\begin{array}{c}\text { ‘ 洛阳 8716’ } \\
\text { ‘ Luoyang 8716’ }\end{array}$ & $\begin{array}{l}\text { ‘ 豫麦 34’ } \\
\text { ‘ Yumai 34’ }\end{array}$ & $\begin{array}{c}\text { ‘ 洛阳 8716’ } \\
\text { ‘ Luoyang 8716’ }\end{array}$ \\
\hline $7 \mathrm{~d}$ & $46.0^{\mathrm{b}}$ & $40.7^{\mathrm{b}}$ & $73.54^{\mathrm{b}}$ & $60.78^{\mathrm{b}}$ & 2.22 & 1.84 \\
\hline $14 \mathrm{~d}$ & $46.1^{\mathrm{b}}$ & $41.2^{\mathrm{b}}$ & $72.24^{\mathrm{b}}$ & $64.17^{\mathrm{a}}$ & 2.17 & 1.94 \\
\hline $21 \mathrm{~d}$ & $43.6^{c}$ & $38.1^{\mathrm{c}}$ & $70.15^{\mathrm{bc}}$ & $61.04^{\mathrm{b}}$ & 2.11 & 1.85 \\
\hline $28 \mathrm{~d}$ & $43.3^{c}$ & $38.5^{\mathrm{c}}$ & $67.55^{\mathrm{c}}$ & $57.92^{\mathrm{c}}$ & 2.15 & 1.80 \\
\hline$(7+14) d$ & $50.0^{\mathrm{a}}$ & $45.3^{\mathrm{a}}$ & $81.61^{\mathrm{a}}$ & $62.34^{\mathrm{ab}}$ & 2.18 & 1.64 \\
\hline$(7+21) d$ & $47.2^{\mathrm{ab}}$ & $43.6^{\mathrm{ab}}$ & $69.63^{\mathrm{bc}}$ & $59.74^{\mathrm{b}}$ & 1.84 & 1.56 \\
\hline$(7+14+21+28) d$ & $47.7^{\mathrm{ab}}$ & $44.7^{\mathrm{a}}$ & $73.28^{\mathrm{b}}$ & $61.30^{\mathrm{ab}}$ & 1.57 & 1.29 \\
\hline CK & $42.5^{\mathrm{c}}$ & $41.3^{\mathrm{b}}$ & $64.75^{\mathrm{d}}$ & $58.43^{\mathrm{c}}$ & 2.21 & 2.05 \\
\hline
\end{tabular}

品种内处理间差异的显著性检验用 LSR 多重比较法 ,不同小写英文字母表示差异达到 5\%的显著水平 Different small letters showed the 5\% significant levels with Duncan's method among different treatments

WUE : Water use efficiency

理中节水潜力较大 ;而 洛阳 8716' 应保证后期水分 供应 才能充分发挥其高产潜力。

\section{3 讨 论}

关于后期灌水对小麦品质的影响，国内外已经 有较为深入的研究。有研究认为, 后期干旱条件下 籽粒湿面筋含量、沉降值、面团形成时间、稳定时间 等均高于灌水处理( Nagarajan ,1999; ;石惠恩, 1988;山 仑,1983)，但也有与此相反的结论（王绍中等, 1995)。毛凤梧等 (2001) 用灌浆期灌水结合施用氮 素处理, 发现灌浆期浇水, 可使面粉的沉降值、湿面 筋、干面筋、形成时间、稳定时间增加 弱化度有一定 程度的下降。Mann 等 (2001) 试验表明灌浆末期干 旱导致面团形成时间降低,面筋弹性降低, Gooding 等 (2003) 试验表明灌浆末期干旱降低 SDS-沉降值。 试验结果的不同, 可能是由于不同品种的基因型表 现、灌水量的大小、灌溉方法不同而产生差异。本研 究在开花后进行不同的水分处理结果为, 两品种湿 面筋含量均以不灌水的处理 CK 和开花后 $21 \mathrm{~d}$ 灌水 的处理较高, 以灌 4 次水的处理含量最低。两种筋 型小麦品种对开花后不同灌水处理的面团流变学特 性影响为, 开花后灌 1 次水, 沉降值、面团形成时间、 稳定时间、评价值等有随灌溉时间推迟而提高的趋 势; 开花后灌多次水, 上述品质指标数值有随灌水次 数增多而下降的趋势。开花后 $21 \mathrm{~d}$ 和 $28 \mathrm{~d}$ 灌水处 理的多项品质指标都大于 $\mathrm{CK}$ 。许多学者研究了小 麦品质与产量之间的相关性, 表明决定品质与籽粒 产量的基因有一定程度上的独立分离性, 培育出高 产、优质的基因型是可能的(荆奇等,1999)。而在大 田生产中, 通过栽培措施调控各生态因子而实现高 产优质也是可行的。本研究也表明, 产量与各品质
指标之间并没有呈现出显著的负相关关系, 而且对 于弱筋小麦品种 洛阳 8716', 产量与品质要求呈现 显著性的正相关关系。

节水灌溉对我国小麦生产具有重要的意义。我 国干旱、半干旱地区面积占全国土地面积的一半以 上 $\left(52.5 \%\right.$ ), 此区约有耕地面积 3800 万 $\mathrm{hm}^{2}$ (兰林 旺等,1995)。我国小麦主产区水资源严重不足，在 黄淮海平原 1600 万公顷耕地中, 具备灌溉条件 (小 麦正常用水)的面积只有 400 万公顷，而且降水偏 少，冬小麦全生育期降水量只占总需水量的 40\% 50\%（王晨阳等，1998），因此，水分是该区冬小麦生 产的主要限制因子。许多研究认为, 在一定范围内, 小麦产量随着耗水量的增加而呈线性关系增加。根 据王树安等(兰林旺等, 1995)研究, 小麦全生育期耗 水量为 $405 \mathrm{~mm}$ 时, 产量可达 $6240 \mathrm{~kg} \mathrm{hm}^{-2}$ 。程宪 国等 (1996) 研究指出, 耗水量在 $168.7 \sim 238 \mathrm{~mm}$ 之 间, 产量为 $630 \sim 1875 \mathrm{~kg} \mathrm{hm}^{-2}$;耗水量在 315 347 $\mathrm{mm}$ 之间时, 产量为 $4500 \mathrm{~kg} \mathrm{hm}^{-2}$ 。在本研究中, 两 种筋型小麦品种在全生育期人工控制浇水 (灌水量 180 315 mm) 和严格防止天然降水条件下，小麦耗 水量 (314 477 mm) 虽然较低, 但仍获得了较高的产 量 (5 792 8 $\left.161 \mathrm{~kg} \mathrm{hm}^{-2}\right)$, 且绝大多数处理的水分 利用效率均在 $1.80 \mathrm{~g} \mathrm{~mm}^{-1} \cdot \mathrm{m}^{-2}$ 以上, 最高可达 $2.22 \mathrm{~g} \mathrm{~mm}^{-1} \mathrm{~m}^{-2}$ 。灌溉水利用效率在品种间和处 理间有一定差异。' 豫麦 34' 所有处理在节水灌溉条 件下仍能获得高产, 水分利用效率较高, 而洛阳 8716' 要发挥其高产潜力，必须注意生育后期的水分 供应。本研究试验地点地下水位为 $4 \sim 5 \mathrm{~m}$, 很有可 能对冬小麦耗水产生影响，由于未考虑地下水的补 给作用, 可能存在小麦耗水量计算偏低、水分利用效 率偏高的问题, 但作为品种间和处理间相互比较, 相 
对结果应当是可信的。综合考虑小麦的生态限制因 子、产量和品质； 豫麦 34’ 7 和 14 两个处理较好的 协调了产量与品质关系, 产量与品质均表现突出, 而 且灌水也不多。在弱筋型小考 洛阳 8716' 中 , (7+ 14) d、 $(7+14+21+28) d$ 两个处理较好的重合了品 质与产量的兼容性, 使产量与品质同步提高, 开花后 $7 \mathrm{~d}$ 和 $14 \mathrm{~d}$ 尽量灌两水, 但是同时也应当注意灌水量 和灌水成本，以期小麦生产达到优质高产高效。

\section{参 考 文 献}

Anjunm, F. M. \& D. R. Drake. 2000. Grain, flour and breadmaking properties of eight Pakistan hard white spring wheat cultivars grown at three different locations for 3 years. International Journal of Food Science and Technology, 35: $407 \sim 416$.

Cao, G. C. (曹广才) \& S. Z. Wang(王绍中). 1994. Wheat quality ecology. Beijing: Chinese Science and Technology Press. $145 \sim 167,89 \sim 92,38 \sim 39$. (in Chinese)

Cheng, X.G. (程宪国), D.S. Wang (汪德水) \& M. R. Zhang (张美荣). 1996. Effects of different water content on growth and nutrition absorption of winter wheat. Acta Agriculturae Sinica (中国农业科学), 29(4): 67 74. (in Chinese with English abstract)

Chen, R.M. (陈如梅) \& J.H.Ma(马俊虎). 1992. Primary report on the changes of protein content and component of grain in filling stage of wheat. Journal of Shanghai Agriculture(上海农业 学报), 8: $34 \sim 37$. (in Chinese with English abstract)

Corbellini, M., M. G. Canevar, L. Mazza \& B. Borghi. 1997. Effect of the duration and intensity of heat shock during grain filling on dry matter and protein accumulation, technological quality and protein composition in bread and durum wheat. Australian Journal of Plant Physiology, 24: $245 \sim 260$.

Fullington, J.G., D. M. Miskelly, C. W. Wrigley \& D.D. Kasarda. 1987. Quality related endosperm proteins in sulfur deficient and normal wheat grain. Journal of Cereal Science, 5: 233 246.

Gao, J.H. (郜俊红), X.Z. Liao(廖祥政), X.J. Liao(廖先 静) \& T. W. Lei(雷体文). 2003. Effects of irrigation on quality and yield of strong gluten wheat. Farming and Cultivation (耕 作与栽培), (2):37 38. (in Chinese with English abstract)

Gooding, M. J., R. H. Ellis, P. R. Shewry \& J. D. Schofield. 2003. Effects of restricted water availability and increased temperature on the grain filling, drying and quality of winter wheat. Journal of Cereal Science, 37: $295 \sim 309$.

Guo,T. C. (郭天财) \& Z. H. Wang (王志红). 1988. Henan wheat production and technology. Zhengzhou: Henan Science and Technology Press. 310 345. (in Chinese)

Irani, P. S. 1998. Effect of amount and time of nitrogen application as top dressing on yield and quality of Ghods wheat cultivars. Seed and Plant, 14: $101 \sim 109$.

Jin, Q. (荆奇), W.X. Cao(曹卫星) \& T. B. Dai(戴廷波). 1999. Advance of quality formation and development of wheat. Tritical Crops (麦类作物), 19(4) : 46 51. (in Chinese with English abstract)

Jin, S. B. (金善宝). 1996. Chinese wheat sciences. Beijing: China Agriculture Press. 928 929. (in Chinese)

Jin, H.F. (靳华芬) . 1992. The relationship of ecological factors and quality of winter wheat. In: Lin, Z.J. (林作楫) ed. Theory and application of winter wheat in China. Hangzhou: Zhejiang
Sciences and Technology Press. 167 181. (in Chinese)

Lan, L.W. (兰林旺) \& D. X. Zhou(周殿胥). 1995. Study on water-saving irrigation and high yield in wheat. Beijing: Beijing Agricultural University Press. $312 \sim 334$. (in Chinese)

Li, Y.G. (李永庚), G.M. Jiang(蒋高明) \& J.C. Yang(杨景 成). 2003. Effects of temperature on carbon and nitrogen metabolism, yield and quality of wheat. Acta Phytoecologica Sini$\mathrm{ca}($ 植物生态学报), $27: 164 \sim 169$. (in Chinese with English abstract)

Liang, Y. L. (梁银丽) \& S.Z. Kang (康绍忠). 2000. The effects of soil moisture and nitrogen and phosphorus addition on carbon isotope discrimination and water use efficiency in wheat. Acta Phytoecologica Sinica (植物生态学报), 24:289 292. (in Chinese with English abstract)

Liu, Z. Y. (刘尊英), T. C. Guo(郭天财) \& Y.J. Zhu (朱云 集). 1999. Effects of nitrogen supply on protein component and accumulation of wheat. Journal of Henan Agricultural University (河南农业大学学报), 33: $317 \sim 320$. (in Chinese with English abstract)

López-Bellido, L., R. J. López-Bellido, J. E. Castillo \& F. J. López-Bellido. 2001. Effects of long-term tillage, crop rotation and nitrogen fertilization on bread-making quality of hard red spring wheat. Field Crops Research, 72:197 210.

Lu, L.S. (卢良恕). 1993. The new advance of wheat cultivating in China. Beijing: China Agriculture Press. $491 \sim 496$. (in Chinese)

Mann, G., J. Graaf, J.D. Schofield, M.J. Gooding, R.H. Ellis \& P. Greenwell. 2001. Functional and biochemical effects on wheat of water availability and growth temperature during grain filling. In: Association of Applied Biologists eds. Aspects of applied biology 64, wheat quality. Warwick : Warwick Press. 137 $\sim 138$.

Mao, F.W. (毛风梧) \& H.J. Zhao (赵会杰). 2001. A primary study of the effects of phosphorus fertilizer application on the wheat quality on the alluvial soil. Journal of Hennan Agricultural University (河南农业大学学报), 35: $400 \sim 402$. (in Chinese with English abstract)

Mekendry, A.L., G.E. Henke \& P.L. Finney. 1995. Effects of septoria leaf bloch on soft red winter milling and baking quality. Cereal Chemistry, 72: $142 \sim 146$.

Mikhaylenko, G. G., Z. Czuchajowska, B. K. Baik \& K. K. Kidwell. 2000. Environmental influences on flour composition, dough rheology, and baking quality of spring wheat. Cereal Chemistry, 77:501 511 .

Nagarajan, S. 1999. Effects of post-anthesis water stress on accumulation of dry matter, carbon and nitrogen and their partitioning in wheat varieties differing in drought tolerance. Journal of Agronomy and Crop Science, 18: 129 136 .

Panozzo, J.F. \& H. A. Eagles. 2000. Cultivar and environmental effects on quality characters in wheat. II. Protein. Australian Journal of Agricultural Research, 51: 629 636 .

Rharrabti, Y., D. Villegas, C. Royo, V. Martos-Núñez \& L. F. García-Moral. 2003. Durum wheat quality in mediterranean environments: II. Influence of climatic variables and relationships between quality parameters. Field Crops Research, 80:133 140 .

San, L. (山乞). 1983. Study on plant water in China Northwest and improving yield in arid area. Plant Physiology Communications (植物生理学通讯), 5:7 10. (in Chinese with English abstract)

Shi, H.E. (石惠恩) . 1988. Study on the changes of protein content and yield in grain maturity process of wheat. Journal of 
Henan Vocation-Technical Teachers College (河南职业技术师 范学院学报), 4:59 65. (in Chinese with English abstract)

Singh, A. K. 2000. Effects of sowing time, irrigation and nitrogen on grain yield and quality of durum wheat. Indian Journal of Agricultural Sciences, 70:532 533 .

Tohansson, E., M. L. Prieto-Linde \& J. Ö. Jönsson. 2001. Effects of wheat cultivars and nitrogen application on storage protein composition and bread making quality. Cereal Chemistry, 78:19 $\sim 25$.

Tribioi, E., A. Abad., A. Michelena., J. Lloveras., J. L. Ollier \& C. Daniel. 2000. Environmental effects on the quality of two wheat genotypes: 1. Quantitive and qualitative variation of storage protein. European Journal of Agronomy, 13: $47 \sim 64$.

Wang, C. Y. (王晨阳) \& J. X. Li (李九星). 1998. Water resource in wheat production area in northern China and its effective utilization. Henan Agricultural Sciences and Technology (河南 农业科技)，(8): 7 10. (in Chinese with English abstract)

Wang, H. (王鸿) \& W. C. Zhao(赵万春). 2000. The genotype and environmental effect of winter wheat. Shaanxi Agricultural Science(陕西农业科学), 9: 3 5. (in Chinese)

Wang, S.Z. (王绍中) \& C.X. Li(李春喜).1995. Wheat quality and difference in Henan Province. Henan Agricultural Science (河南农业科学), 10: 3 10. (in Chinese)
Wang, Y.Q. (汪永钦) \& H.Y. Yang(杨海鹰).1990. The relationship between grain quality of winter wheat and meteorologic conditions. Agricultural Meteorology(中国农业气象), 11:1 7. (in Chinese with English abstract)

Zhang, B. J. (张宝军) \& J. Y. Jiang(蒋纪芸). 1995. Quality of wheat and its affection factors. Foreign Agronomy: Wheat and Barley Crops (国外农学一一麦类作物 ), 4: 29 31. (in Chinese)

Zhang, L.H. (章练红), S.Z. Wang (王绍中) \& Y.J. Li(李运 景). 1984. View and perspective on research of quality ecology of winter wheat. Foreign Agronomy: Wheat and Barley Crops(国 外农学一一麦类作物), 6: $42 \sim 45$. (in Chinese)

Zhang, L.H. (章练红), S.Z. Wang (王绍中) \& Y.J. Li (李运 景). 1993. Advances of wheat quality ecology research. Chinese Agricultural Bulletin(中国农学通报),9(6): 11 16. (in Chinese with English abstract)

Zhang, L.H. (章练红). 1988. Effects of natural ecological conditions on quality of wheat. World Agriculture (世界农业), 5: $21 \sim 24$. (in Chinese)

Zhao, N.X. (赵乃新), X.H.Gu (顾小红) \& J. Lan(兰静). 1998. Study on the relationship of quality and protein composition of winter wheat. Tritical Crops (麦类作物 ), 18(4): $44 \sim 47$. (in Chinese with English abstract) 